\title{
CATADORAS DE MATERIALRECICLÁVEL: ARTICULAÇÕES ENTRE TECNOLOGIA, TRABALHO E GÊNERO
}

\section{Collectors of recyclable material: linkages between technology, work and gender}

\author{
Daniela Isabel Kuhn ${ }^{24}$ \\ Nanci Stancki da Luz ${ }^{25}$
}

\section{Resumo}

Neste artigo refletimos sobre o desenvolvimento da tecnologia relacionada ao mundo do trabalho de catadoras de material reciclável, articulando com os estudos de gênero e da divisão sexual do trabalho. Para tanto, partimos de uma revisão de alguns aspectos dos alicerces históricos da atualidade, como a instauração da modernidade e do sistema capitalista, e discutimos sobre as características desta atividade laboral. Desta forma, pretendemos construir bases teóricas e reflexivas para um estudo sobre a identidade das mulheres catadoras de material reciclável.

Palavras-chave: catadoras de material reciclável - tecnologia - trabalho gênero

\section{Abstract}

In this paper we reflect on the development of technology related to the world of work pickers of recyclable material in approach to studying the theories of gender. Therefore, we start with a review of some aspects of the historical foundations of today, such as the establishment of modernity and the capitalist system, and we discussed the characteristics of this work activities. Thus, we intend to build theoretical and reflective for a study on women's identity pickers of recyclable materials.

Doutoranda do Programa de pós-graduação em Tecnologia e Sociedade - PPGTE/UTFPR kuhndaniela@hotmail.com. 
Key words: pickers of recyclable materials - technology - work - relations

\section{Introdução}

Em síntese, a tecnologia é uma fonte de poder. Nela, os homens se instalam para exercer e garantir o seu poder em outras áreas. Ela conforma nossas vidas e estrutura o que e como fazemos, como vivemos as relações sociais e o significado do ser humano.

Maria Helena Santana Cruz

A epígrafe que inicia este texto sintetiza dois aspectos que tem sido fonte de estudo nas áreas de pesquisa tecnologia e sociedade e nos estudos de gênero. O primeiro é uma reflexão crítica sobre a ciência, a técnica e a tecnologia, adotando uma abordagem avessa ao determinismo tecnológico e que encara estes saberes como construções sociais complexas e que, portanto, como processo social, participam e condicionam as mediações sociais, não determinam por si só a realidade, não são autônomas, nem neutras e nem somente experimentos, técnicas, artefatos ou máquinas; constituem- se na interação ação-reflexão-ação de práticas, saberes e conhecimentos: são, portanto, trabalho, relações sociais objetivadas (LIMA FILHO; QUELUZ, 2005, p. 20)

Alicerçado no entendimento de que ciência e tecnologia expressam ideologias, o segundo aspecto diz respeito a encarar que neste ideário estão arraigados princípios do patriarcado. Neste sentido, o texto da epígrafe deve ser lido compreendendo a palavra "homens" como direcionada apenas para os homens, e não como temos sido acostumados culturalmente - "homens" como sinônimo de seres humanos, tendência quase universal de reduzir a raça humana a apenas a esta parcela ${ }^{26}$. Desta forma, um aspecto complementa o outro, pois entendemos que tendo como pressuposto que ciência

26 Esta é uma das críticas que o movimento feminista tem realizado ao longo de décadas de pesquisa e estudos acadêmicos. Refere-se ao entendimento de que o uso da linguagem tem sido um forte determinante de poder, no qual está presente tanto a marca do domínio do homem e como da opressão da mulher. A própria autora da epígrafe comenta sobre esta crítica: "A palavra é forte porque tem sentido, significado, na conversação, nos jogos da linguagem. Esses jogos estão presentes em todos os tipos de interação, ao dar e receber ordens, ao descrever alguma coisa, ao especular sobre um evento, ao inventar ou contar palavras, conforme pressupostos habermasianos da Teoria da Ação Comunicativa" (CRUZ, 2002, p. 125) 
e tecnologia contêm e expressam política e ideologia, um dos braços fortes destes saberes e práticas tende para os valores disseminados pela cultura do patriarcado. As concepções políticas e ideológicas são incorporadas nos próprios artefatos, como argumentado no clássico artigo "Do Artifacts have Politics?" de Langdom Winner (1986), embora o autor não discuta especificamente sobre a ideologia do patriarcado.

Nossa atual pesquisa enfoca estudar as relações entre a atividade laboral realizada por catadoras de material reciclável e a identidade como mulher das trabalhadoras e tem demandado reflexões sobre as possíveis articulações entre tecnologia, trabalho e patriarcado. Deste modo, neste artigo apresentamos uma discussão sobre como podemos pensar o desenvolvimento da tecnologia relacionada ao mundo do trabalho sob a luz dos estudos das teorias de gênero.

O artigo, então, foi organizado da seguinte maneira: na primeira parte expomos a trajetória da pesquisa de doutorado que estamos desenvolvendo que enfoca o trabalho de catadoras de material reciclável, explicitando como esta temática conduziu-nos a questão central deste texto. Em seguida, apresentamos uma breve contextualização histórica sobre as relações entre desenvolvimento tecnológico, o projeto da modernidade no Brasil e do sistema capitalista, que fundaram as bases para que o consumo fosse uma atividade altamente presente na contemporaneidade. Argumentamos que apenas com este alto grau de consumo é possível existir a atividade laboral de reciclagem de material. No terceiro tópico propomos uma articulação entre a concepção crítica apresentada na parte anterior com os estudos das teorias de gênero, apresentando como as configurações das ideologias inerentes aos saberes e práticas da ciência e da tecnologia têm expressado subordinação e opressão às mulheres. Na conclusão o leitor encontra uma reflexão sobre como este estudo pode colaborar para um entendimento mais consistente sobre a vida das mulheres catadoras de material reciclável.

\section{Contextualizando a pesquisa}

Durante 2009 a 2011 trabalhamos em um projeto de extensão intitulado: "Do Lixo à Dança:Resgate da Identidade Pessoal e Coletiva dos Catadores de Material Reciclável de Piraquara- PR"27 em uma associação de catadores 
e catadoras de material reciclável na cidade de Piraquara-PR, região metropolitana de Curitiba. As diversas ações desenvolvidas neste projeto geraram vários questionamentos e inquietações que fundamentaram a proposição de um projeto de pesquisa (doutorado), que vem sendo desenvolvido no Programa de Pós-Graduação em Tecnologia da Universidade Tecnológica Federal do Paraná (PPGTE/UTFPR).

Como a maioria entre as trabalhadoras e os trabalhadores da associação eram mulheres, o universo feminino do lixo foi ganhando mais força em nosso projeto de extensão gerando indagações a respeito da relação de cada catadora com o lixo e sua identidade como mulher. As questões que nasceram partiram da observação das tarefas cotidianas, das conversas que realizamos e das condições nas quais se realiza a atividade de catação.

Cabe mencionar que outras pesquisas realizadas com catadores e catadoras de material reciclável em diferentes partes do Brasil também indicam uma maioria de mulheres nesta atividade, como nas teses de doutorado de Feitosa (2005) e de Martins (2004), ambas em Porto Alegre e no estudo de Silveira (2011) no município de São Paulo.

Este é um trabalho realizado por mulheres, mas com características que contrastam com estereótipos do que tem sido considerados como trabalho feminino - que demanda pouca força, coordenação fina, vinculado a um padrão de beleza, a um ideal de fragilidade (ADELMAN, 2003). Isto porque ser catadora requer muita força física, permanecer num local muito sujo, com forte odor de lixo, em condições que expõe o corpo da trabalhadora a sujeira, a cortes e machucados por presença de materiais pérfuro-cortantes junto ao material, bem como a doenças, devido, por exemplo, à convivência com roedores no ambiente de trabalho e o encaminhamento equivocado de lixo não reciclável altamente perigoso, como material hospitalar.

Desta forma, estas condições laborais contrastam com percepções sobre trabalho feminino que apontam para atividades que não exigiriam força física na sua execução atributo que estaria associado à percepção do tra-

27 O projeto de extensão "Do Lixo à Dança: Resgate da Identidade Pessoal e Coletiva dos Catadores de Material Reciclável de Piraquara- PR" foi coordenado pela Prof ${ }^{a}$ Daniela Kuhn e a Prof ${ }^{a}$ Leandra Ulbricht foi atuante em nosso projeto, foi realizado em colaboração com a UFPR, sob a coordenação da Profa Marcia Oliveira.. Contou com financiamento da Fundação Araucária de duas formas: bolsa de extensão do programa "Ações Afirmativas" para a aluna Luiza Santini e financiamento do espetáculo de dança e do documentário pelo edital de "Pesquisa Básica e Aplicada". 
balho masculino.

A percepção de que as mulheres não teriam força física, seriam dotadas de delicadeza e seriam seres mais frágeis as aproximariam de atividades consideradas leves e fáceis, evidencia que a realidade das catadoras contrasta com essa perspectiva essencialista, pois presenciamos inúmeras vezes estas mulheres carregarem o material reciclável prensado extremamente pesado do fundo do barracão até a porta.

A atividade laboral da mulher ainda tem sido associada aquelas que têm como característica cuidado, amor, carinho, limpeza e organização. 0 estudo das relações do trabalho das catadoras com estas características será um dos focos de nossa pesquisa. Reconhecemos, neste momento, elementos de organização e cuidado na ação de separação dos materiais. Contudo, chama-nos a atenção que nas condições de trabalho destas muIheres na lida com o lixo, coloca-as em contato constante com a sujeira e o mal cheiro, contrastando com o fator limpeza elencado como característica.

Diante deste cenário, emerge uma questão basilar para este estudo: por que este trabalho que contrasta em alguns aspectos com o estereótipo mencionado tem tido uma presença significativa de mulheres?

Uma possibilidade de resposta reside em refletirmos sobre a inserção da mulher no mercado de trabalho e o chamado trabalho "precário". Para tanto, nos reportamos a Danièle Kergoat (2003) e Helena Hirata (2002, 2009), duas das principais representantes do estudo da divisão sexual de trabalho. As autoras enfatizam a importância da luta histórica contra a dominação masculina e reivindicam a igualdade entre direitos para ambos os sexos. Neste sentido, fundamentam suas pesquisas em um princípio: "a exploração por meio do trabalho assalariado e a exploração do feminino pelo masculino são indissociáveis, sendo a esfera das relações de classe aquela em que, simultaneamente é exercido o poder dos homens sobre as mulheres" (HIRATA, 2002, p.277). Embasada nesta percepção em suas pesquisas Hirata (2009) relata que os indicadores do que vem a ser trabalho precário ${ }^{28}$, demonstram a existência de uma contundente divisão sexual de precariedade, pois é maior o número de mulheres inseridas no

28 A autora define o trabalho precário a partir de três indicadores: ausência de proteção social e de direitos sociais; horas reduzidas de trabalho e, consequentemente, salários baixos e baixos níveis de qualificação. 
trabalho informal e também no trabalho em tempo parcial.

Portanto, a princípio temos um quadro com duas perspectivas, que, como veremos, complementam-se. Inicialmente ponderamos que estas muIheres catadoras realizam uma atividade laboral que contrasta tanto com um estereótipo de fragilidade e beleza feminina contrapondo-se ao que se "espera" no senso comum de um trabalho feminino. Por outro lado, as condições de trabalho das catadoras corroboram com a maneira que muitas mulheres têm adentrado no mundo do trabalho: de maneira informal, ausência de proteção social e de direitos sociais, trabalho em tempo parcial associado a salários baixos e baixos níveis de qualificação.

Estas primeiras inferências conduzem a outras indagações: este trabaIho configura-se para estas mulheres como uma escolha ou trata-se do que "sobrou" para sua labuta de própria sobrevivência e de sua família? Que concepções ideológicas de tecnologia e trabalho estariam presentes nos determinantes de formatação deste trabalho?

\section{O trabalho das catadoras: desenvolvimento tecnológico, sistema capitalista e consumo}

Adotamos uma abordagem que considera a tecnologia como construção social, tendo suas repercussões que refletem sobre as múltiplas dimensões da organização do trabalho, como por exemplo "as mudanças nos paradigmas de produção, a precarização do trabalho e as alterações nas exigências de qualificação da classe trabalhadora" (LUZ; QUELUZ; NASCIMENTO, 2011, p. 11).

Assim o conceito de tecnologia torna-se abrangente e amplo, diferente de um senso comum que associa mais usualmente tecnologia aos artefatos eletrônicos existentes atualmente. Além disso, levamos em consideração as diversas fases de desenvolvimento tecnológico da humanidade, pois entendemos que a técnica e a tecnologia conquistada pela humanidade, nas suas diversas e heterogêneas tradições, configurações e evoluções, são consequências de um longo caminho percorrido, permeado de "descobertas", fissuras, falhas e acertos. Assim, são os saberes apreendidos pelas pessoas ao longo do tempo que possibilitam o desenvolvimento de novas tecnologias.

A necessidade humana de solucionar problemas (ou o que determinado 
grupo social encara como um problema) foi um dos principais combustíveis que alimentou o desenvolvimento tecnológico ao longo da evolução humana. Contudo, mesmo entendendo que este não foi um desenvolvimento histórico linear, quanto menos um processo homogêneo universal, sabemos que, em nenhum outro período histórico o desenvolvimento tecnológico teve uma velocidade tão acelerada, bem como, tão permeável socialmente. Nos dias atuais a tecnologia assume uma presença marcante no cotidiano, estando presente em todas as dimensões da vida social, seja na esfera do lar, do trabalho ou do lazer, seja no espaço público ou no privado. Assim a tecnologia, ou o que se representa como tecnologia, assume papel central na sociabilidade, ou seja, na produção da realidade e do imaginário (universo real e simbólico) ( LIMA FILHO; QUELUZ, 2005, p. 20).

Pensar no trabalho das catadoras implica, portanto, considerar que este ocorre inserido neste contexto de intensa presença da tecnologia no cotidiano, sendo uma atividade laboral que se configura no sistema capitalista e na perspectiva atual dos processos de globalização. Ambos são influenciados profundamente pelos avanços científicos e tecnológicos que provocam alterações nos processos produtivos, de comunicação, educacionais, nas formas de consumo, além de mudar a relação das pessoas com o meio ambiente, gerando inúmeras implicações.

Neste sentido, a fim de contextualizar estas tendências econômicas, sociais e culturais, reportarmo-nos a Nicolau Sevcenko ${ }^{29}$ ao enfocar as transformações tecnológicas do final do século XIX e início do século seguinte no Brasil, propõe compreender "tanto as novas mudanças provocadas pela introdução das novas técnicas e modos de vida quanto os efeitos da construção dos mitos da modernidade e da cidade moderna" (SEVCENKO, 1998, p. 523).

Estamos falando de um período da chegada da modernidade nesta

29 Ao adotarmos este autor como referência, cabe salientar que apesar de ser significativa para nossas reflexões sua contribuição da leitura histórica que faz sobre o projeto da modernidade, sua concepção da relação entre tecnologia e sociedade diferem daquela adotada por nós. Sevcenko aparenta ainda estar vinculado a uma concepção que considera que a tecnologia impacta a sociedade, mas não aborda a outra via, ou seja, as influências dos seres humanos no desenvolvimento da ciência e da tecnologia. Quando escolhemos discutir sobre as ideologias presentes nestas áreas, é indispensável considerar que os homens e as mulheres, suas ideias, crenças e valores influenciam profundamente a trajetória do desenvolvimento científico e tecnológico. 
sociedade, na qual se instaura uma nova ordem social racionalizada, que tem como modelo a modernidade já consolidada nos Estados Unidos e na Europa. Este modelo ganhou força principalmente com os meios de comunicação de massa, frutos do desenvolvimento científico e tecnológico, como a revista, o rádio e, mais tarde, a televisão. É neste contexto que são impulsionados tanto o aumento da produção de mercadorias, como estimulados o seu consumo, com a disseminação de um de seus principais mecanismos: a publicidade. Neste processo estabelece-se que os artefatos tem carga simbólica da modernidade.

Uma primeira consequência de adentrarmos neste contexto histórico é perceber que apenas com o alto grau de consumo das classes mais favorecidas - realidade nutrida pelo fetichismo da mercadoria já anunciada por Marx - torna-se possível uma produção de lixo reciclável suficiente para que o trabalho de catação destes resíduos possa existir. E para que o consumo esteja sempre acontecendo, é necessário que existam sempre novas mercadorias. Estas novas mercadorias são dependentes dos avanços da ciência e da tecnologia, que geram novos materiais, reconfiguração dos antigos, artefatos inovadores em suas funções, design e aplicabilidade da vida contemporânea, geralmente vinculados a status social.

Se no século $X X$ a aceleração nas mudanças tecnológicas, as grandes guerras e a globalização marcaram este período, preparam terreno para o projeto da modernidade e a instauração do sistema capitalista (SEVCENKO, 2001), na atualidade colhemos algumas das consequências destas transformações. Uma delas é o consumo como maneira de construir identidades.

Em seus estudos sobre catadores de material reciclável, Cunha (2009) lembra-nos que na chamada modernidade tardia o consumo assume o papel de formatar as identidades, como uma matéria-prima contínua e obsessiva. Nesta lógica a construção da identidade está vinculada aquilo que cada um(a) consome, influenciando nossas relações e ambientes. Identificamos que se instaura a "síndrome consumista" (BAUMAN, 2005).

Este consumo tem se configurado como extremamente voraz e veloz, resultando uma dinâmica que irá gerar nos indivíduos o desejo de renovação, de substituição. A ação de descartar acaba significando a possibilidade de não ser "descartado", não ser considerado out, não ser "jogado no lixo", espaço que ninguém deseja estar. Desta forma, o lixo assume um papel central neste cenário. Segundo Cunha (2009b, p.186) é dele que se origina o bem-estar da sociedade. Na sociedade contemporânea o lixo torna-se 
o local dos excluídos, com identidade social deteriorada.

Temos en-

tão que o consumo - resultado do modelo de modernidade e da dinâmica do sistema capitalista, ambos nutridos pelo desenvolvimento da ciência e da tecnologia - é condição essencial para a existência do material de trabalho das catadoras: o lixo reciclável.

Entendemos, consequentemente, que a inserção desta trabalhadora no mercado de trabalho ocorre de maneira perversa, pois o contexto aponta ser a própria desigualdade social que acaba sustentando a atividade laboral de separação do material reciclável. Uma realidade social na qual poucos podem consumir muito e, desta forma, produzir material reciclável em quantidade tão grande que tem sido suficiente para gerar a atividade profissional de muitas catadoras, atividade marcada atualmente por condições indignas de sobrevivência. Nesta distorção, cabe aqui ampliar nossa questão: além de uma maioria de mulheres atuarem como catadoras em um tipo de trabalho considerado precário, quais as ideologias inseridas na lógica descrita acima? Se existia um projeto de sociedade diretamente relacionado aos avanços tecnológicos, qual o projeto mulher que se anunciava?

\section{O projeto de sociedade e o projeto de mulher}

O desenvolvimento tecnológico que ocorreu a partir da década de 70 gerou transformações dos contextos locais, culturais, com repercussão no cotidiano, nas relações sociais, e colaboraram para que alguns valores do patriarcado se reafirmassem, gerando segregação e opressão a muitas muIheres (CRUZ, 2002).

Manuel Castells(1999) considera que todas as sociedades contemporâneas se assentaram sobre a estrutura do patriarcado, que tem como características o uso da autoridade, imposta institucionalmente, do homem sobre a mulher e filhos no âmbito familiar. Para que esta autoridade possa ser exercida, é necessário que o patriarcalismo permeie toda a organização da sociedade, da produção e do consumo à política, à legislação e à cultura. Os relacionamentos interpessoais e consequentemente, a personalidade, também são marcados pela dominação e violência que têm sua origem na cultura e nas instituições do patriarcado (CASTELLS, 1999, p. 167).

Deste modo, se a cultura do patriarcado está incorporada nas políticas e ideologias, no consumo e na produção, não fica difícil vislumbrarmos que 
se tecnologia contém e expressa ideologias o patriarcado é uma delas. Para Cruz (2002) historicamente a ciência e a tecnologia esteve alheia ao domínio feminino, como aponta baseada nos argumentos Cockburn (1990).

Sobre o controle masculino, a tecnologia produzida para ser usada pelas mulheres pode ser sumamente inapropriada para as suas necessidades, inclusive perniciosa e, pode ainda incorporar ideologias masculinas que determinam como devem elas viver. Assim, consumam-se, a alienação e a exclusão das mulheres no âmbito tecnológico (CRUZ, 2002, p. 128).

As transformações sociais nos aspectos físicos, econômicos, sociais e culturais dos primórdios do projeto da modernidade influenciaram a dimensão material da vida social. Configuraram-se mudanças nas rotinas corporais das mulheres no meio urbano e geraram os processos de inculcação, destacando a relevância do corpo e à corporalidade (CARVALHO, 2002

Michel Foucault (2011) - em "Vigiar e Punir" - já anunciou com contundência como o controle é conquistado no corpo, por meio de imposições e padrões "normais" de conduta estabelecida pela sociedade. A disciplina na sociedade moderna é vista pelo autor como uma técnica de produção de corpos dóceis ${ }^{30}$.

No final do século XIX a cultura do patriarcado se concretiza no corpo da mulher, através da imposição de novos hábitos sociais (CARVALHO, 2008). Com a introdução dos ideais da modernidade, foi necessário romper com antigos hábitos de sobriedade para que o consumo fosse estimulado.

30 Por estes motivos que muitas teóricas feministas adotam suas ideias para fundamentar seus trabalhos, pois seus estudos auxiliam na compreensão das relações de poder dos homens em relação às mulheres. Porém é interessante assinalar algumas críticas realizadas por Susan Bordo (2000), importante teórica feminista, em seu artigo "A feminista como o outro", sobre as relações estabelecidas entre as teorias de gênero e os estudos de Michel Foucault. Mesmo adotando um forte traço foucaultiano em seus trabalhos - tendo escrito um artigo em 1997 intitulado "O corpo e a reprodução da feminidade: uma apropriação feminista de Foucault" - Bordo realiza um crítica que diz respeito a ser atribuído quase sempre a Foucault como o "teórico do corpo", obscurecendo várias teorias realizadas pelos estudos de gênero. Bordo reivindica que seja reconhecido que o discurso de Foucault não é neutro em relação a gênero, como querem alguns, como por exemplo, na sua clássica leitura do corpo do soldado, em "Vigiar e Punir". 
O ideário do projeto burguês exigiu o engajamento da mulher na rotina doméstica, mas existiram outros fatores de natureza econômica que a fixaram em casa: diminuir a concorrência no mercado de trabalho (no caso dos operários). Neste processo, a produção de representações femininas no espaço doméstico "inclui ativamente o corpo na constituição de sua identidade" (CARVALHO, 2008, p. 224).

Desta forma, consideramos o ideal burguês e posteriormente da modernidade contribuíram para uma organização social que foi impulsionada pelo avanço tecnológico. Esta sociedade demandou e desejou um projeto de muIher que estivesse de acordo principalmente com os interesses econômicos do sistema capitalista. Estes interesses moldaram atitudes, escolhas, valores, que permeiam e atravessam várias esferas como a social e a cultural.

Complementando estes argumentos, devemos abordar que existe uma problematização sobre a crença de que a divisão de trabalho estaria baseada equivocadamente nas limitações naturais impostas às mulheres. Paola Tabet (2005) demonstra que esta falsa crença se desfaz perante vários trabalhos extenuantes e que envolvem carregar materiais muito pesados que as mulheres de algumas comunidades realizam. A pesquisadora assume o intuito de demonstrar "como o monopólio de certas atividades-chave é essencial para garantir aos homens controle dos meios de produção e, em última instância, a utilização global de mulheres" (TABET, 2005, p. 74) ) $^{31}$.

Com estas discussões evidencia-se como a tecnologia e a ciência detêm ideologia e política e podem ser mais alienantes, injusta, desigual ou mais igualitário, conscientizadora e justa.

\section{Considerações Finais}

Para analisarmos as possíveis relações entre o trabalho com o material reciclável e como as catadoras constroem suas identidades de mulher, consideramos ser fundamental uma reflexão sobre as interfaces entre tecnologia, trabalho e as relações de gênero. Nesta perspectiva, reconhecemos a relevância dos aspectos históricos nos quais se assenta a cultura do patriarcado na contemporaneidade, e da discussão sobre a instauração da modernidade e da organização do sistema capitalista, ambos nutridos pelos 
avanços nas áreas da ciência e da tecnologia.

Argumentamos que na ciência e na tecnologia estão presentes ideologias, sendo uma delas a do patriarcado, que imprime em homens e mulheres valores, crenças e hábitos. Desta forma, consideramos que "embora os significados possam variar de uma cultura para outra, qualquer sistema de sexo-gênero está sempre intimamente interligado a fatores políticos e econômicos em cada sociedade" (LAURETIS, 1994, p. 211). Portanto, na realidade da atividade laboral das catadoras, no exercício cotidiano do sistema sexo-gênero que atua nas relações interpessoais destas mulheres, estão presentes características relacionadas aos aspectos políticos e econômicos da sociedade. Esta configuração gera os determinantes de manutenção ou alteração de uma condição social.

Ao realizarmos uma leitura de que o trabalho das catadoras de material reciclável não pode ser considerado emancipatório e de rompimento com o capitalismo, mais sim com uma "estratégia de resistência e sobrevivência" (COUTINHO, 2004), devemos acrescentar discussões sobre os meandros que tecem estas relações de poder e de classes, particularmente relacionada ao patriarcado e seus contornos, expressões e domínios.

Nesta persepctiva, tecnologia e trabalho também têm sido fundamentadas nesta senda de valores do patriarcado, como as teorias de gênero vêm discutindo. Quando adotamos a perspectiva de que a técnica, a tecnologia e seus artefatos não são neutros, nem determinam nosso "progresso", podemos desvendar os desdobramentos de significados, sentidos e poderes que atuam na história e no cotidiano de cada pessoa. Este pressuposto conduz a compreensão de que qualquer tecnologia não resulta de um caminho único, mas deriva de uma cadeia de processos, possibilidades e escolhas, estando permeada de valores, ideais e concepções políticas. Assumir esta perspectiva retira-nos da comodidade da ingenuidade e coloca-nos na responsabilidade de pesquisadores engajados em propor maneiras de se viver de forma mais digna e igualitária.

A reflexão sobre como funciona os poderes enraizados pela cultura do patriarcado no âmbito da atividade laboral das catadoras, pode colaborar para a conscientização e autonomia destas mulheres. Pode significar uma chave para que se abram portas de caminhos mais férteis na condução de um trabalho digno, deixando de alinhar-se às condições de um trabalho precário. 


\section{Referências}

ADELMAN, Miriam. Mulheres atletas: re-significações da corporalidade feminina. Rev. Estudos Feministas, Florianópolis, v. 11, n. 2, Dec. 2003 . Disponível em: http://www.scielo.br/scielo.php?script=sci_arttext\&pid=S0104-026X2003000200006\&lng=en\&nrm=iso >. Accesso 04/01/2013.

BAUMAN, Z. Identidade. Rio de Janeiro: Jorge Zahar, 2005.

CASTELLS, Manuel. A era da informação. Economia, sociedade e cultura. In: CASTELLS, Manuel. A Sociedade em Rede. São Paulo: Paz e Terra. 2000. V. 1.

CARVALHO, Vânia Carneiro de.Gênero e artefato: o sistema doméstico na perspectiva da cultura material - São Paulo, 1870-1920. São Paulo: Edusp; Fapesp, 2008.

COCKBURN, Cynthia. Tecnical competence, gender identity and women's autonomy. Trabalho apresentado ao $12^{\circ}$ World Congress of Sociology, Madrid, 1990.

COUTINHO, M. C. O lixo como estratégia de sobrevivência: apsicologia nas organizações solidárias, 2004. Disponível em: <http://www.extensio. ufsc.br/20042/Direitos_Humanos_CFH_Maria_Chalfim.pdf>. Acesso em: 06 jan. 2013

CRUZ, Maria Helena Santana. Novas tecnologias e impacto sobre as muIheres, In: COSTA, A. A. A. C.; SANDENBERG, C. M. B. (org.) (2002). Feminismo, Ciência e Tecnologia, Salvador: REDOR/NEIM-FFCH/UFBA, 2002. disponível em: http://www.neim.ufba.br/site/arquivos/file/feminismocienciencia.pdf . Acesso em: 04.jan. 2013

MARTINS, Clitia Helena Backx, Trabalhadores na reciclagem do lixo: dinâmicas econômicas, socioambientais e políticas na perspectiva de empoderamento. Porto Alegre: FEE, 2004.

MATOS, Marlise. Teorias de gênero ou teorias e gênero? Se e como os estudos de gênero e feministas se transformaram em um campo novo para as ciências. Rev. Estud. Fem., Florianópolis, v. 16, n. 2, Aug. 2008 . Disponível em <http://www.scielo.br/scielo.php?script=sci_arttext\&pid=S0104-026X20 08000200003\&Ing=en\&nrm=iso>. Acesso em 10/01/ 2013.

FEITOSA, Débora Alves. Cuidado e Sustentação da Vida: a interface da Educação Popular no Cotidiano de mulheres recicladoras. Porto Alegre: PP- 
GEDU/UFRGS, 2005. Tese de doutorado. Orientadora: Profa. Dra. Malvina do Amaral Dorneles.

HIRATA, Helena. Nova Divisão Sexual do Trabalho? Um olhar voltado para a empresa e a sociedade. São Paulo: Boitempo Editorial, 2002.

HIRATA, Helena. A Precarização e a Divisão Internacional e Sexual do Trabalho. In: Sociologias, on-line, Porto Alegre, ano 11, n.21, jan-junho, 2009. Disponível em: http://www.seer.ufrgs.br/index.php/sociologias/article/view/8854. Acesso em: 15/10/2012

KERGOAT, Danièle. Divisão Sexual do Trabalho e Relações Sociais de Sexo. In: Trabalho e Cidadania Ativa para as Mulheres: desafios para as Políticas Públicas. São Paulo: Coordenadoria Especial da Mulher, 2003. MÉSZÁROS, István. O Poder da Ideologia. São Paulo: Boitempo Editorial. 2004.

LAURETIS, Teresa de. "A tecnologia do gênero". In: HOLLANDA, Heloísa Buarque de (org.). Tendências e impasses: o feminismo como crítica da cultura. Rio de Janeiro: Rocco, 1994, p. 206-242.

LIMA FILHO, D. L.; QUELUZ, G. A tecnologia e a educação tecnológica: elementos para uma sistematização conceitual. Educação \& Tecnologia, Belo Horizonte, v. 10, n. 1, p. 19-28, 2005.

LUZ, Nanci Stancki da; NASCIMENTO, Décio Estevão do, QUELUZ, Marilda Lopes Pinheiro ; Apresentação. In: Tecnologia e transformação social: reflexões sobre gênero, trabalho e educação. Curitiba: Ed. UTFPR, 2011.

SEVCENKO, Nicolau. A Corrida para o Século XXI: no Loop da Montanha Russa. São Paulo: Companhia das Letras, 2001.

SEVCENKO, Nicolau. História da Vida Privada no Brasil (vol.3) - República: da Belle Epoque à Era do radio. São Paulo: Cia das Letras, 1998. pp. 514-619 (capítulo 7).

TABET, Paola. Las manos, los instrumentos, las armas. In: CURIEL, Ochy; FALQUET, Jules (orga). El patriarcado al desnudo: tres feministas materialistas. Collete Guillaumin, Paola Tabet, Nicole Claude Mathieu. Buenos Aires: BrechaLésbica, 2005. p.129.

WINNER, Langdon. Do artifacts have politics? In: Mackenzie, Donald \& Wajcman, Judy. The SocialShaping of Technology. Buckingham, Philadelphia: Open University Press, 1986, tradução para o português disponível em: http://www.necso.ufrj.br/Trads/Artefatos\%20tem\%20Politica.htm 